\title{
DISTRIBUSI JARINGAN MENGGUNAKAN ROUTING OSPF DENGAN METODE REDISTRIBUTION
}

\author{
Adia Pratama Nugraha Permana \\ Fakultas Teknik, Program Studi Teknik Informatika \\ Universitas BSI Bandung \\ Email: kisahsiber@gmail.com \\ Ricky Firmansyah \\ AMIK BSI Bandung \\ Email: ricky.rym@bsi.ac.id
}

\begin{abstract}
ABSTRAK
Pembangunan jaringan komputer dari satu area menjadi beberapa area akan menggunakan beberapa router sebagai gateway, maka manajemen jaringan resikonya akan semakin besar dan rumit. Sehingga dibutuhkan pengaturan routing dengan jarak yang terpendek dan cepat dalam mengirimkan paket-paket data sampai ke tujuan. Penelitian ini fokus pada bagaimana membuat sebuah topologi jaringan yang baru dimana routing OSPF diterapkan pada jalur utama dan menerapkan Redistribution pada setiap router yang terhubung kepada masing- masing client sebagai penghubung dan penerus distribusi routing dari jalur utama menuju jalur client. Bertepatan dengan bertambahnya router di sebuah area akan bertambah pula informasi yang harus dimiliki oleh router pada area yang sama dalam waktu yang sama, maka OSPF lah yang paling tepat untuk proses routing tersebut. Redistribution adalah metode routing yang digunakan untuk meredistribusikan atau meneruskan suatu routing ke routing yang lain agar dapat saling menukarkan atau men-advertise routing table masing-masing. Hasil penelitian ini, berdasarkan pada penjumlahan nilai metric dijkstra dengan metric redistribute pada penelitian ini, jalur terbaik (best path) dengan nilai metric yang lebih kecil akan dipilih sebagai jalur pendistribusian terbaik dari best path lain yang memilik metric yang lebih besar. Selain itu, redistribution dapat menghubungkan routing dynamic OSPF dengan routing static yang terhubung pada masing-masing client.
\end{abstract}

Kata kunci: jaringan komputer, OSPF, redistribute, route.

\begin{abstract}
Build a computer network from one area to multiple areas will use multiple routers as a gateway, makes network risk management will be even greater and more complicated. So it takes the routing settings with the shortest distance and fast in sending data packets to the destination. This research focuses on how to create a new network topology where OSPF routing is implemented on the main path and implement Redistribution on each router connected to each client as a link and router routing distribution from the main path to the client path. Coinciding with increasing the router in an area will also increase the information that must be owned by the router in the same area at the same time, the OSPF is the most appropriate for the routing process. Redistribution is a routing method used to redistribute or forward a routing to another routing in order to exchange or advertise each other's routing table. The result of this paper based on the metrics summation with metric redistribute in this study, the best path with value smaller metrics will be selected as the best distribution path from other best paths that have larger metrics. In addition, redistribution can connect dynamic OSPF routing with static routing connected to each client.
\end{abstract}

Keywords: computer network, OSPF, redistribute, route.

\section{PENDAHULUAN}

\subsection{Latar Belakang}

Jaringan komputer memungkinkan kelompok kerja berkomunikasi lebih efisien, memberikan kemampuan kepada media komunikasi untuk mempercepat proses kerja yang lebih baik dari segi ruang dan waktu dimana semuanya membantu team lebih produktif (Munandar \& Badrul, 2015). Ketika pembangunan jaringan komputer dari satu area menjadi beberapa area akan menggunakan beberapa router sebagai gateway, maka manajemen jaringan resikonya akan semakin besar dan rumit. Sehingga dibutuhkan 
pengaturan routing dengan jarak yang terpendek dan cepat dalam mengirimkan paket-paket data sampai ke tujuan (Achmad, 2015). Open Shortest Path First (OSPF) adalah salah satu jenis routing, lebih baik, lebih kuat, lebih cepat dari pendahulunya. OSPF di rancang untuk melampaui kemampuan dari keterbatasan distance vector routing. Bertepatan dengan bertambahnya router di sebuah area akan bertambah pula informasi yang harus dimiliki oleh router pada area yang sama dalam waktu yang sama. maka OSPF lah yang paling tepat untuk proses routing tersebut (Dwiyanto, Putra, \& Krisnaningsih, 2015). Akan tetapi, OSPF tidaklah sempurna. Oleh karena itu, kadangkala kita perlu menentukan dan memprediksi traffic secara manual. Sebagai contoh, beberapa aplikasi firewall, voice, dan aplikasi tertentu mengharuskan kita untuk menentukan rute traffic secara manual. Redistribution adalah metode routing yang digunakan untuk meredistribusikan atau meneruskan suatu routing ke routing yang lain agar dapat saling menukarkan atau meng-advertise routing table masing-masing (Masykur, 2016).

Perkembangan teknologi jaringan komputer dan internet dapat dirasakan oleh setiap lapisan masyarakat termasuk suatu lembaga atau instansi salah satunya adalah sekolah. Tidak hanya menjadi tempat belajar bagi para siswanya, sekolah merupakan tempat bekerja bagi karyawan yang ada seperti kepala sekolah, wakil kepala sekolah, staff administrasi, pustakawan, dan lain-lain. SMK Unggulan Terpadu PGII Bandung atau SMK UT PGII merupakan salah satu unit sekolah dibawah Yayasan Pendidikan PGII selain dari empat unit lainnya yaitu SMP PGII 1 Bandung, SMA PGII 1 Bandung, SMP PGII 2 Bandung dan SMA PGII 2 Bandung. Mengingat kebutuhan jaringan komputer begitu penting di SMK UT PGII terutama untuk pertukaran data yang cepat dan mudah tidak hanya dalam ruang lingkup SMK UT PGII saja tetapi dengan unit-unit sekolah di bawah Yayasan Pendidikan PGII lainnya, maka untuk mengatasi masalah di atas perlu dibangunnya suatu rancangan baru agar jaringan komputer di masing masing unit dapat terhubung satu sama lain dan bekerja secara maksimal. Berdasarkan pada uraian di atas, penelitian ini fokus pada bagaimana membuat sebuah topologi jaringan yang baru dimana routing OSPF diterapkan pada jalur utama (backbone) dan menerapkan Redistribution pada setiap router yang terhubung kepada masing- masing client sebagai penghubung dan penerus distribusi routing dari jalur utama (backbone) menuju jalur client.

\subsection{Tinjauan Pustaka}

\subsubsection{Jaringan Komputer}

Jaringan komputer adalah suatu sistem yang terdiri atas komputer dan perangkat jaringan lainnya yang bekerja sama untuk mencapai tujuan tertentu (Firmansyah, 2014). Tujuan dari jaringan komputer adalah untuk berkomunikasi dan berbagi sumber daya, baik penggunaan software maupun hardware. Jaringan komputer dapat terbentuk apabila terdapat lebih dari satu komputer yang dihubungkan menggunakan media transmisi. Media transmisi yang digunakan dapat berupa kabel, gelombang radio maupun cahaya tergantung daripada kebutuhan. Jaringan komputer dapat terhubung dengan hardware maupun software dari berbagai vendor karena telah memiliki standarisasi secara internasional. Internet merupakan jaringan komputer terbesar yang dapat menghubungkan komputer dari dan ke seluruh dunia. Walaupun internet merupakan jaringan komputer, internet dapat diakses melalui perangkat lain seperti laptop, tablet/smartphone, gadget, smart TV, IP camera maupun perangkat lainnya yang memiliki standarisasi jaringan komputer. Setiap perangkat yang terhubung dalam jaringan harus memiliki alamat unik yang dikenal dengan nama alamat IP (IP Address). Disebut unik karena alamat tersebut harus berbeda antara satu dan yang lainnya. Terdapat dua versi IP Address yang digunakan saat ini yaitu IPv4 dan IPv6 (Firmansyah, 2018).

\subsubsection{Routing}

Routing merupakan proses dimana sesuatu dibawa dari satu lokasi ke lokasi lainnya. Contoh riil sesuatu yang membutuhkan perutean adalah surat, panggilan telepon, perjalanan kereta api, dan lain sebagainya. Pada suatu jaringan router adalah perangkat yang digunakan untuk merutekan trafik jaringan. Untuk dapat melakukan perutean, suatu router, atau entitas apapun yang membangun routing, melakukan beberapa langkah berikut ini:

a. Mengetahui Alamat tujuan

b. Mengenali sumber-sumber informasi perutean.

c. Menemukan rute-rute.

Pada suatu sistem jaringan komputer, router mempelajari informasi routing dari sumber-sumber routing-nya yang terletak di dalam tabel routing (routing table). Router akan berpedoman pada tabel ini untuk menyatakan port mana yang digunakan memforward paket-paket yang ditujukan kepadanya (Edi, 2006). 


\subsubsection{Open Shortest Path First (OSPF)}

Open Shortest Path First (OSPF) adalah salah satu jenis routing, lebih baik, lebih kuat, lebih cepat dari pendahulunya. OSPF di rancang untuk melampaui kemampuan dari keterbatasan distance vector routing. Bertepatan dengan bertambahnya router di sebuah area akan bertambah pula informasi yang harus dimiliki oleh router pada area yang sama dalam waktu yang sama. maka OSPF lah yang paling tepat untuk proses routing tersebut (Dwiyanto, Putra, \& Krisnaningsih, 2015).

\subsubsection{Route Redistribution $(R R)$}

Route Redistribution (RR) adalah pilihan konfigurasi lokal ke router. RR menentukan penyebaran informasi routing dari satu proses protokol ke protokol lain di dalam router yang sama. Salah satu contoh dasar penerapan RR adalah OSPF, router perlu menjalankan proses RIP dan proses OSPF dan menyuntikkan rute OSPF ke instance RIP. Dengan demikian, vendor router memperkenalkan RR untuk mengatasi kebutuhan operasi jaringan. Baru-baru ini terdapat konfigurasi beberapa jaringan kampus/universitas besar menemukan bahwa RR memang banyak digunakan. Namun, bertentangan dengan protokol routing tradisional, yaitu tidak ada standar yang secara formal mendefinisikan fungsionalitas RR. RR telah menjadi bagian integral dari desain jaringan IP, namun kestabilannya tampak peka terhadap kegagalan jaringan dan kesalahan konfigurasi (Le, Xie, \& Zhang, 2008).

\section{METODOLOGI PENELITIAN}

Metode penelitian yang digunakan adalah metode analisa penelitian yaitu analisa kebutuhan, desain, testing dan implementasi. Sedangkan untuk metode pengumpulan data yang secara umum dilakukan yaitu observasi, wawancara, dan studi pustaka. Kebutuhan yang diperlukan untuk menerapkan routing OSPF dan Redistribution pada topologi jaringan yang baru adalah beberapa software dan hardware yang menunjang agar topologi tersebut dapat berjalan dengan baik. Skema jaringan usulan di SMK UT PGII bersama dengan unit-unit sekolah lainnya dibawah Yayasan Pendidikan PGII Bandung menggunakan routing OSPF sebagai metode pencarian rute terpendek dan tercepat serta menerapkan Redistribution sebagai penghubung dan penerus distribusi routing dari jalur utama (backbone) menuju jalur client, maka dilakukan pengujian test menggunakan Ping dan Traceroute serta melakukan perhitungan akhir untuk memproleh jalur terbaik (best path) untuk pendistribusian data dan informasi di skema jaringan usulan. Tahap ini menggunakan software GNS3, Virtual Box dan Mikrotik RouterOS.

\section{HASIL DAN PEMBAHASAN}

Berikut merupakan gambar dari skema jaringan yang dibuat dengan menerapkan routing OSPF dan metode Redistribution.

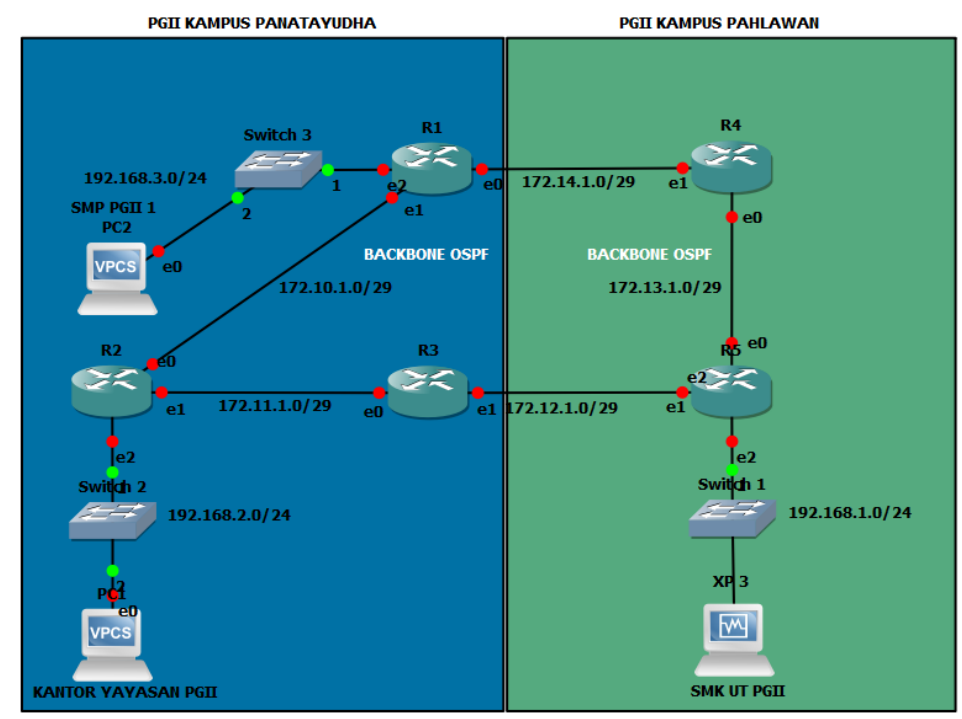

Gambar 1. Skema Jaringan 


\subsection{Rancangan Jaringan}

Konfigurasi pada tahapan rancangan aplikasi di masing-masing router di jalur utama (backbone) menggunakan fitur Command Line Interface (CLI) pada mikrotik RouterOS agar rancangan routing OSPF dengan Metode Redistribution berjalan dengan baik. Sebagai contoh konfigurasi secara menyeluruh diambil dari router R1. Pada point ini seperti pada Gambar 2 bertujuan untuk menambahkan dan menentukan IP address serta interface yang digunakan.

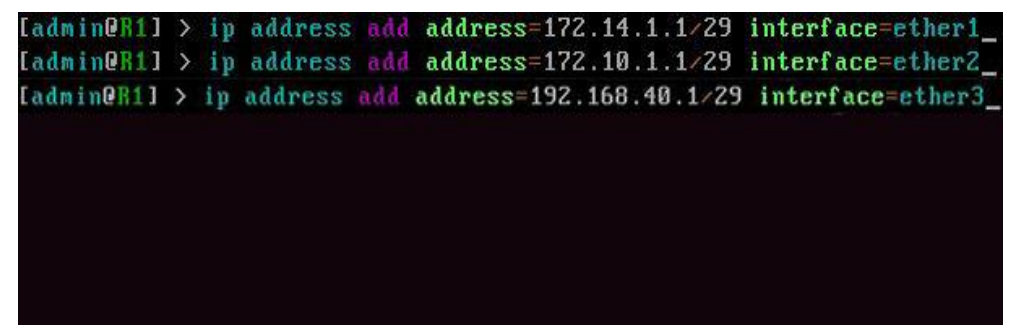

Gambar 2. Konfigurasi IP Router R1

Kelas IP yang digunakan merupakan IP kelas B yaitu 172.14.1.1 dengan prefix /29 untuk jumlah host address sebanyak 6 address dan untuk interface ditentukan pada etherl. Untuk penjelasan konfigurasi routing OSPF di ambil dari router $\mathrm{R} 1$ pada point pertama hal yang harus terlebih dahulu dilakukan adalah menentukan router-id pada routing OSPF dengan menggunakan IP address 172.14.1.1 sebagai router-id. Point kedua seperti yang tertera pada Gambar 3 melakukan konfigurasi routing OSPF pada network 172.14.1.0 dengan prefix /29 yang ada pada router R1, serta area OSPF yang digunakan yaitu jalur utama (backbone).

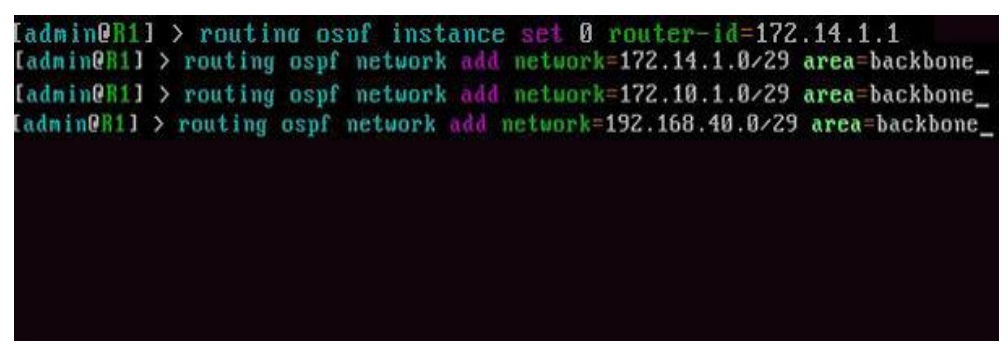

Gambar 3. Konfigurasi OSPF Router R1

Rancangan jaringan usulan ini satu-satunya area OSPF yang digunakan hanyalah pada jalur utama (backbone) saja karena penelitian ini menggunakan sistem single area OSPF. Sedangkan untuk konfigurasi Redistribute sebagai sistem distribusi jaringan dari backbone menuju client dapat dilihat pada Gambar 4. Cara konfigurasi IP Address dan OSPF yang sama juga diterapkan pada setiap router di jalur utama (backbone) yaitu R2 sampai dengan R5.

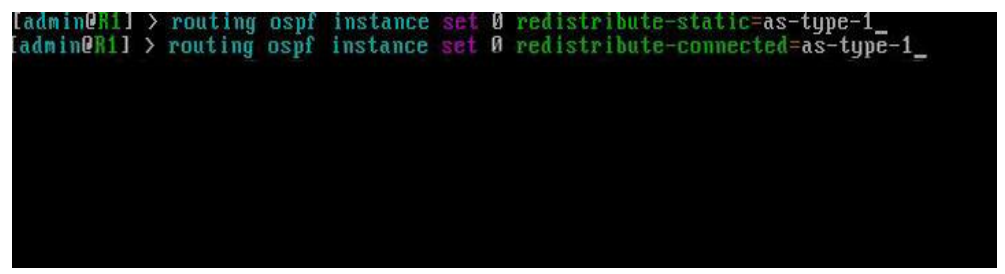

Gambar 4. Konfigurasi Redistribute Router R1

Contoh hasil konfigurasi routing OSPF yang telah dilakukan pada setiap router di jalur utama (backbone) berdasarkan hasil konfigurasi pada router $\mathrm{R} 1$ sebagai berikut : 


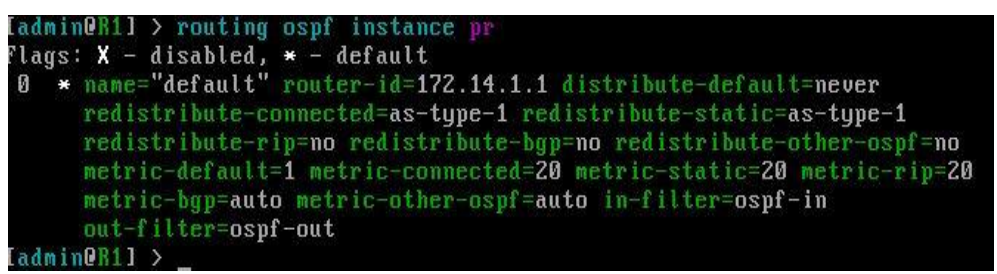

\section{Gambar 5. Routing OSPF Pada Router R1}

Konfigurasi OSPF dan Router-id telah selesai. Konfigurasi Router-id bisa saja tidak dilakukan, tetapi jika tidak dilakukan, maka router yang telah terkonfigurasi oleh OSPF akan memilih IP Address yang memiliki nilai tertinggi pada router interface sebagai Router-id. Sebagai contoh terdapat pada router R1, dimana jika tidak memilih Router-id dengan IP Address 172.14.1.1 maka OSPF akan secara otomatis memilih IP Address dengan nilai tertinggi yang dimiliki router R1 yaitu 192.168.40.1.

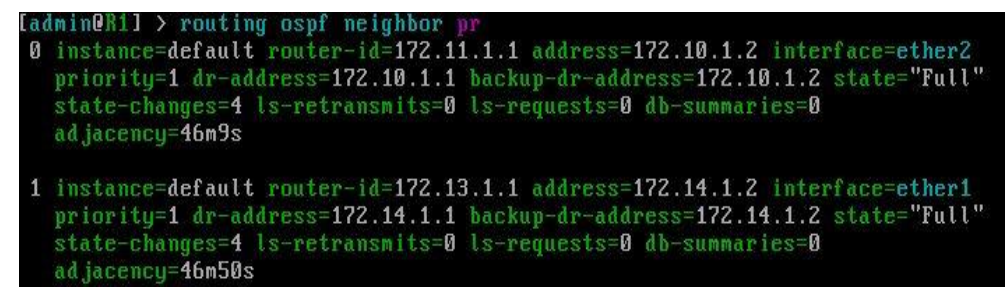

Gambar 6. Neighbor OSPF Router R1

Router R1 telah berhasil melakukan proses pertukaran informasi routing. Pada gambar tersebut memperlihatkan terbentuknya proses adjency router. Yang dimaksud dengan adjency router merupakan proses pertukaran informasi routing dengan router tetangga atau terdekat. Dalam contoh tersebut router R1 telah berhasil melakukan proses pertukaran informasi routing dengan router $\mathrm{R} 2$ yang memiliki Router-id 172.11.1.1 dan router R4 dengan Router-id 172.13.1.1. Dalam proses Adjency Router terdapat dua sistem yang disebut Designated Router (DR) dan Backup Designated Router (BDR). DR merupakan jalur utama dalam proses Adjency Router, dan BDR merupakan jalur backup dalam proses Adjency Router.

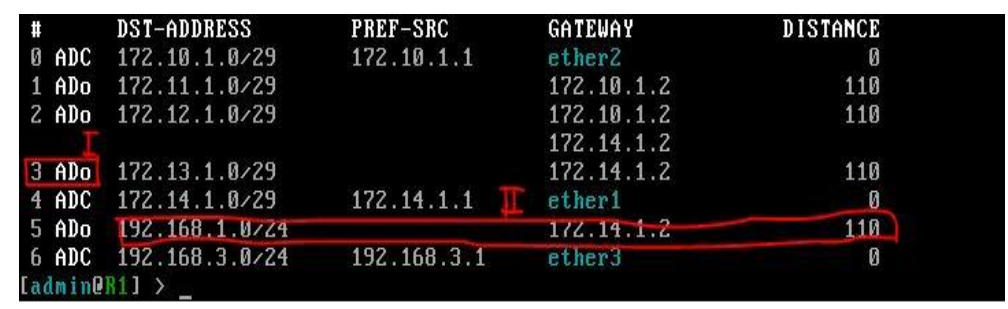

Gambar 7. Table Routing Router R1

Gambar 7 di atas menampilkan informasi update table routing yang berada di router $\mathrm{R} 1$. Untuk point pertama terdapat simbol Active Dynamic OSPF (ADo) yang memperlihatkan bahwa router R1 telah berhasil connected dengan router lain melalui Routing OSPF. Sedangkan point kedua menunjukan update table routing per-network dimana ketika terjadi perubahan informasi routing akan secara otomatis terperbaharui (update). 


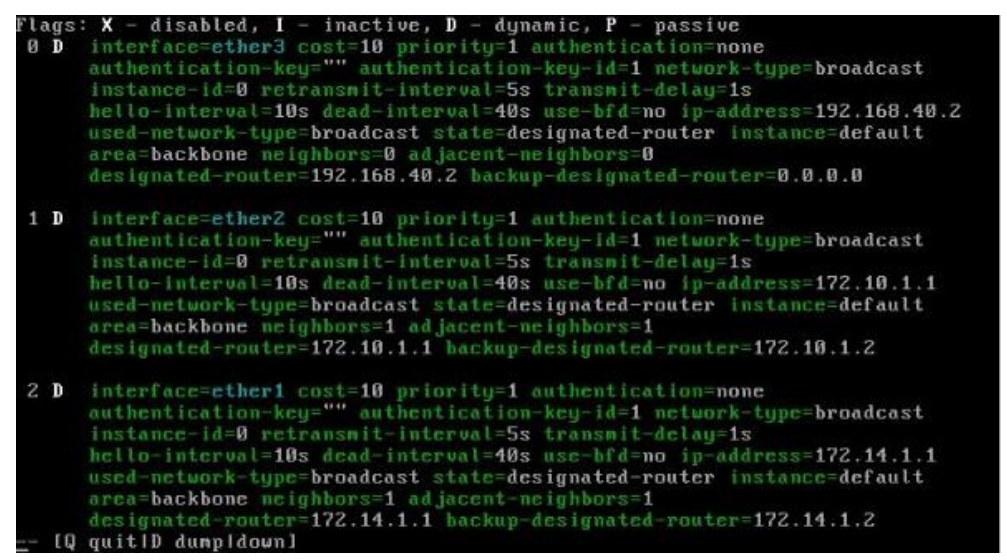

\section{Gambar 8. OSPF Interface Pada Router R1}

Ether1, ether2, dan ether3 pada router R1 telah berhasil terkonfigurasi sebagai bagian dari jalur utama (backbone) di routing OSPF, untuk penjelasan pertama memperlihatkan bahwa masing-masing interface dari etherl hingga ether3 telah diunggah ke jalur utama (backbone). Lalu pada penjelasan kedua proses pemilihan router-id dan type-network telah berhasil dilakukan. Sedangkan pada penjelasan ketiga memperlihatkan Designated Router (DR) dan Backup Designer Router (BDR) dapat digunakan sebagai jalur utama serta backup jalur pertukaran informasi routing. Dan pada penjelasan terakhir memperlihatkan hasil waktu pengiriman Hello Packet (Hello-Interval) antar andjency router sebesar 10 second.

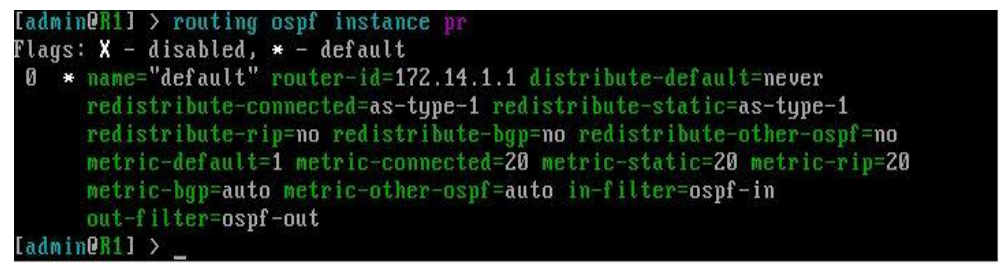

\section{Gambar 9. Hasil Redistribute Router R1}

Gambar 9 di atas Merupakan hasil dari konfigurasi redistribute di router R1 yang terhubung langsung dengan jalur client. Tujuan dari konfigurasi tersebut untuk meneruskan table routing dari jalur utama (backbone) kepada jalur client sehingga dapat saling menukarkan informasi serta menghubungkan dua tipe routing yang berbeda dimana pada jalur utama (backbone) menggunakan dynamic routing yaitu OSPF sedangkan pada jalur client menggunakan static routing.

\subsection{Pengujian Jaringan}

Dalam pengujian ini digunakan ping dan traceroute terhadap koneksi pada masing-masing router yang ada di jalur utama (backbone) ke client atau sebaliknya. Test koneksi dilakukan dari client SMK UT PGII menuju masing-masing router di jalur utama (backbone).

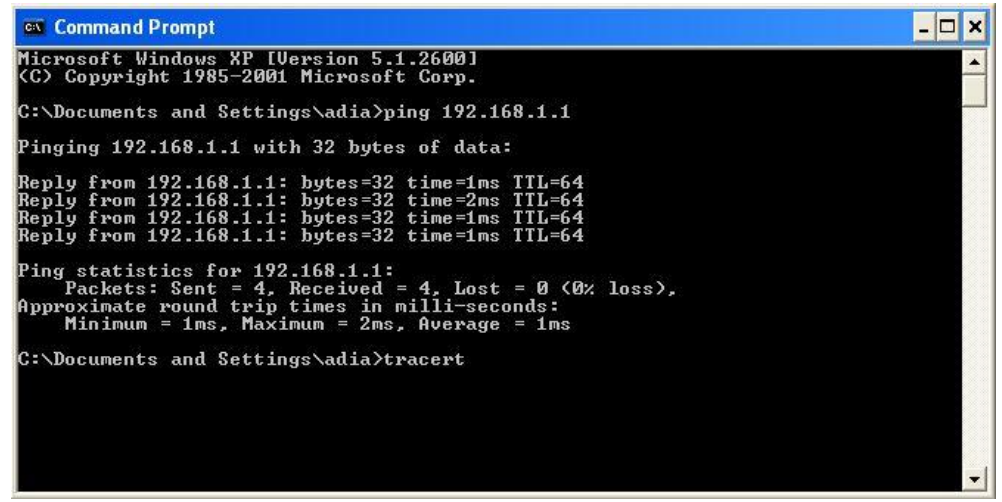

Gambar 10. Test Ping Ke Gateway Router R5 
Gambar 10 di atas merupakan salah satu test diambil dari PC client SMK UT PGII dengan menggunakan ping ke arah gateway router R5. Hasil test terlihat normal.

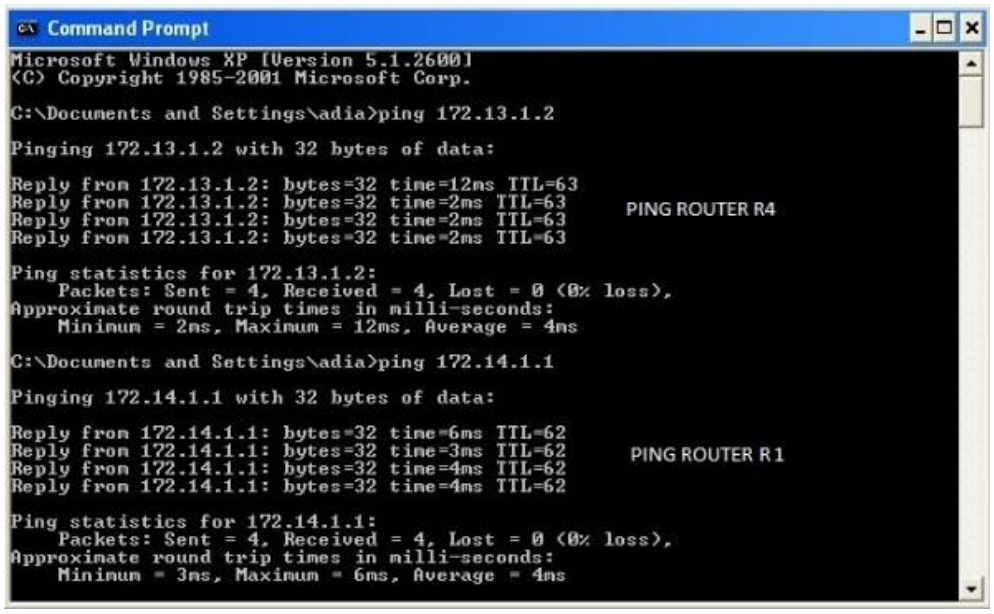

Gambar 11. Test Ping ke Router R4 dan Router R1

Gambar 11 merupakan salah satu test dilakukan dari PC client SMK UT PGII menggunakan ping menuju router $\mathrm{R} 4$ dan router $\mathrm{R} 1$, hasil test terlihat normal.

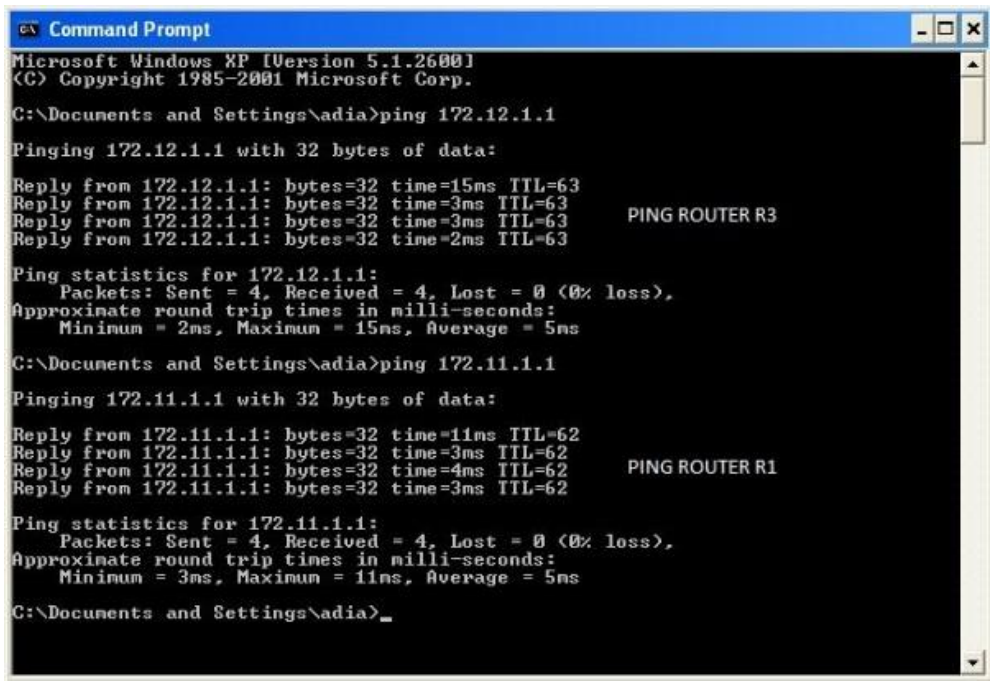

Gambar 12. Hasil Test Ping Ke Router R3 dan Router R2

Gambar 12 di atas menampilkan hasil Test Ping yang terakhir diambil dari PC client SMK UT PGII ke arah router R3 dan R2. Hasil test terlihat normal.

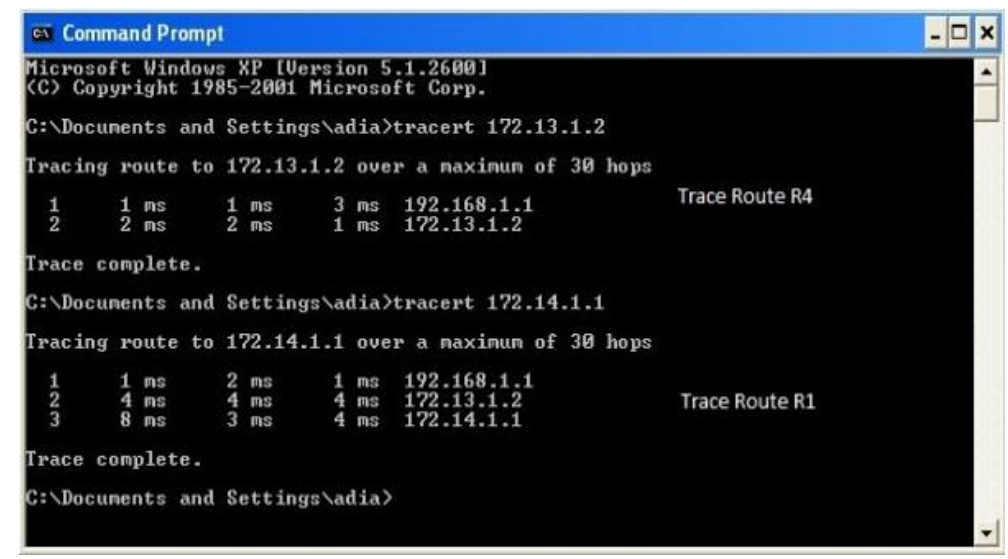

Gambar 13. Hasil Traceroute Ke Router R4 dan Router R1 
Gambar 13 di atas menampilkan proses traceroute kepada router R4 dan router $\mathrm{R} 1$ melalui PC client SMK UT PGII. Hasil akhir dari traceroute menuju router R4 melewati 2 hop, sedangkan menuju router R3 melewati 3 hop.

\subsection{Pengujian Sistem Kerja OSPF}

Ketika sebuah router dalam Routing OSPF belum mencapai kondisi Adjency maka router tersebut tidak akan bisa saling menukarkan informasi. Adapun beberapa point dari sebuah router untuk mencapai kondisi Adjency diantaranya:

\subsubsection{Hello Packet}

Hello Packet akan menentukan apakah router-router yang bertetangga dapat mencapai kondisi Adjency atau tidak. Hello Packet memiliki nama lain yang disebut dengan Router ID (RID).

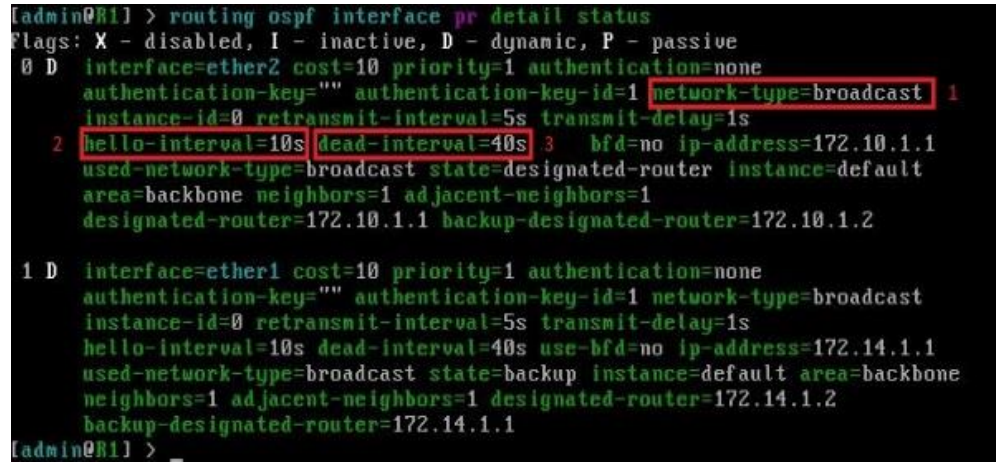

Gambar 14. Informasi Hello Packet pada Router R1

Network Type yang digunakan adalah tipe Broadcast. Hello Packet akan dikirim dengan menggunakan multicast dan akan terbentuk Designated Router (DR) dan Backup Designated Router (BDR). Keterangan Network Type pada Gambar 14 ditandai dengan nomor 1. Dead Interval merupakan waktu yang digunakan untuk menunggu pengiriman paket dari router lain. Pada Gambar 14 tertera bahwa Dead Interval yang dibutuhkan mencapai 40 detik. Dead Interval ditandai dengan nomor 2. Hello Interval merupakan waktu yang dibutuhkan untuk pengiriman paket ke router lain. Pada Gambar 14 tertera bahwa waktu yang dibutuhkan mencapai 10 detik. Hello Interval ditandai dengan nomor 3.

\subsubsection{Database Description $(D B D)$}

Database Description (DBD) berisi paket informasi yang akan dikirimkan kepada router terdekat. Sebelum mampu mengirimkan DBD tersebut, sebuah router tidak akan dapat saling bertukar informasi dengan router terdekatnya.

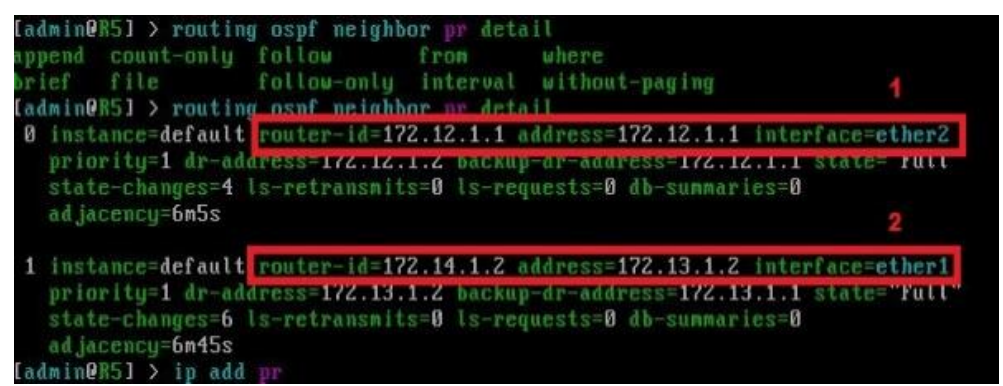

Gambar 15. Informasi Database Description (DBD) Router R5

Sebagai contoh, disini akan dijelaskan paket informasi DBD yang berada di router R5 melalui Gambar 15 pada point pertama router $\mathrm{R} 5$ telah berhasil mengirimkan paket informasi ke router $\mathrm{R} 3$ yang memiliki router-id 172.12.1.1 melalui interface ether2. Sedangkan pada point kedua router R5 telah berhasil pula mengirimkan paket informasi ke router R3 yang memiliki router-id 172.14.1.2 melalui interface ether1. 


\subsubsection{Link State Request (LSR)}

Menurut (Towidjojo, 2016) Link State Request (LSR) digunakan sebuah router untuk meminta informasi yang ada dalam Database milik router lain. Informasi ini bisa saja memiliki informasi spesifik maupun informasi tambahan yang dimiliki oleh router lain. Contoh proses pengiriman LSR oleh dapat dijelaskan pada Gambar 16.

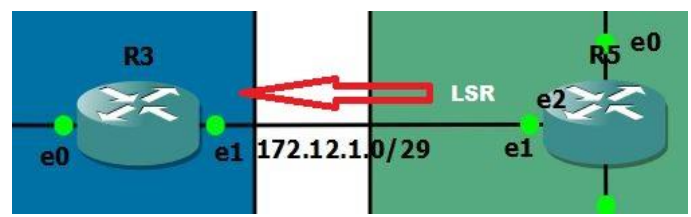

Gambar 16. Proses Kerja Link State Request (LSR)

Berdasarkan pada Gambar 16. router R5 mengirimkan informasi yang di-request oleh router R5 kepada router R3. Hasil dari request yang dilakukan oleh router R5 dapat dilihat dalam Database Description (DR) router R3 seperti dalam Gambar 17.

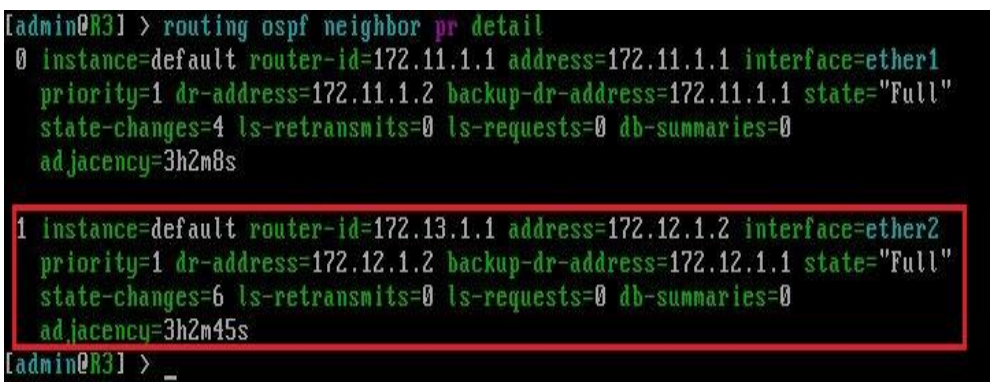

Gambar 17. Link State Reuest Oleh Router R5 di Router R3

\subsubsection{Link State Update (LSU)}

Link State Update (LSU) merupakan paket yang membawa sekumpulan Link State Advertisement (LSA). Banyak LSA yang dapat dibawa oleh sebuah LSU packet dan semuanya digunakan untuk melakukan update informasi routing (Routing Update). Pada gambar 18 dapat dilihat bagaimana LSA beroperasi pada LSU.

\begin{tabular}{|c|c|c|c|c|c|}
\hline AREA & TYPE & ID & ORIGINATOR & SEQUENCE-NU. . . & AGE \\
\hline backbone & router & 172.11 .1 .1 & 172.11 .1 .1 & Ox8000000A & 1445 \\
\hline backbone & router & 172.12 .1 .1 & 172.12 .1 .1 & $0 \times 80000009$ & 1529 \\
\hline backbone & router & 172.13 .1 .1 & 172.13 .1 .1 & Ox8000000A & 1563 \\
\hline backbone & router & 172.14 .1 .1 & 172.14 .1 .1 & $0 \times 8000000 \mathrm{~A}$ & 1476 \\
\hline backbone & router & 172.14 .1 .2 & 172.14 .1 .2 & Ox8000000A & 1517 \\
\hline backbone & network & 172.10 .1 .1 & 172.14 .1 .1 & $0 \times 80000007$ & 1476 \\
\hline backbone & network & 172.11 .1 .2 & 172.12 .1 .1 & $0 \times 80000007$ & 1529 \\
\hline backbone & network & 172.12 .1 .2 & 172.13 .1 .1 & $0 \times 80000007$ & 1563 \\
\hline backbone & network & 172.13 .1 .2 & 172.14 .1 .2 & 0x80000007 & 1616 \\
\hline backbone & network & 172.14 .1 .2 & 172.14 .1 .2 & 0x8000000? & $151 ?$ \\
\hline external & as-external & 192.168 .1 .0 & 172.13 .1 .1 & $0 \times 80000007$ & 1660 \\
\hline external & as-external & 192.168 .3 .0 & 172.14 .1 .1 & $0 \times 80000007$ & 1514 \\
\hline [admineR5] & & & & & \\
\hline
\end{tabular}

Gambar 18. Link State Advertisement pada Router R5

\subsection{Pengujian Jalur Terbaik (Best Path)}

\subsubsection{Jalur Pertama Best Path}

Jalur pertama best path, diambil contoh dari komputer client SMK UT PGII menuju router R1 yang telah ditandai dengan panah pada Gambar 19. Pada jalur best path yang pertama cost pada interface ether3 router R5 bernilai 20, cost kedua pada ether1 router R5 bernilai 10, dan cost ketiga pada ether1 router R1 bernilai 20. Maka total keseluruhan cost pada jalur pertama sebesar 50 cost. 


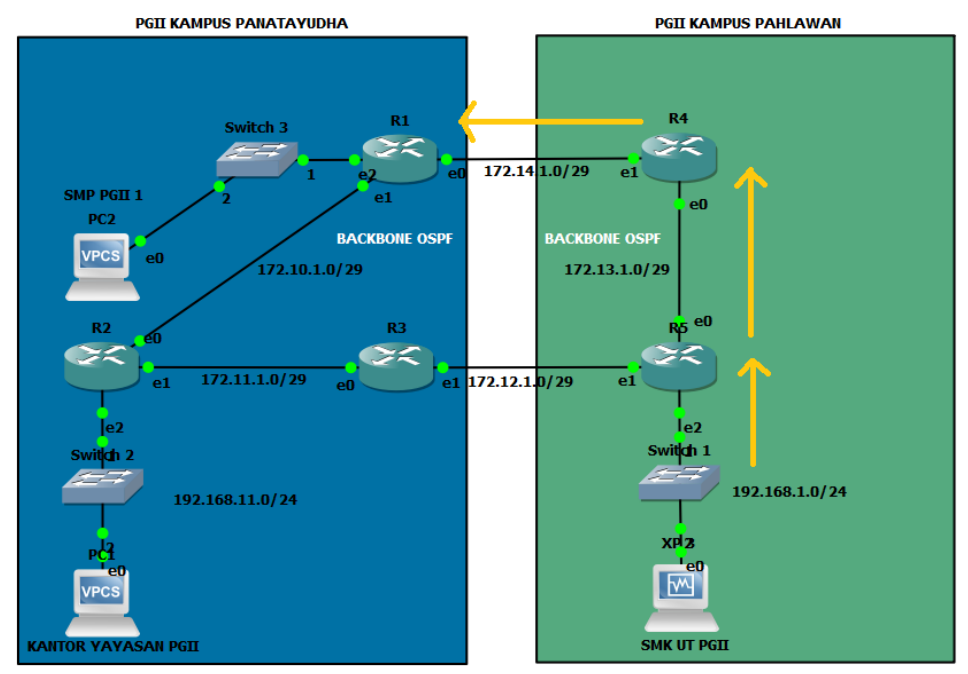

Gambar 19. Jalur Pertama Best Path

Pengujian jalur pertama menggunakan ping dan traceroute dapat dilihat pada gambar 20 di bawah ini.

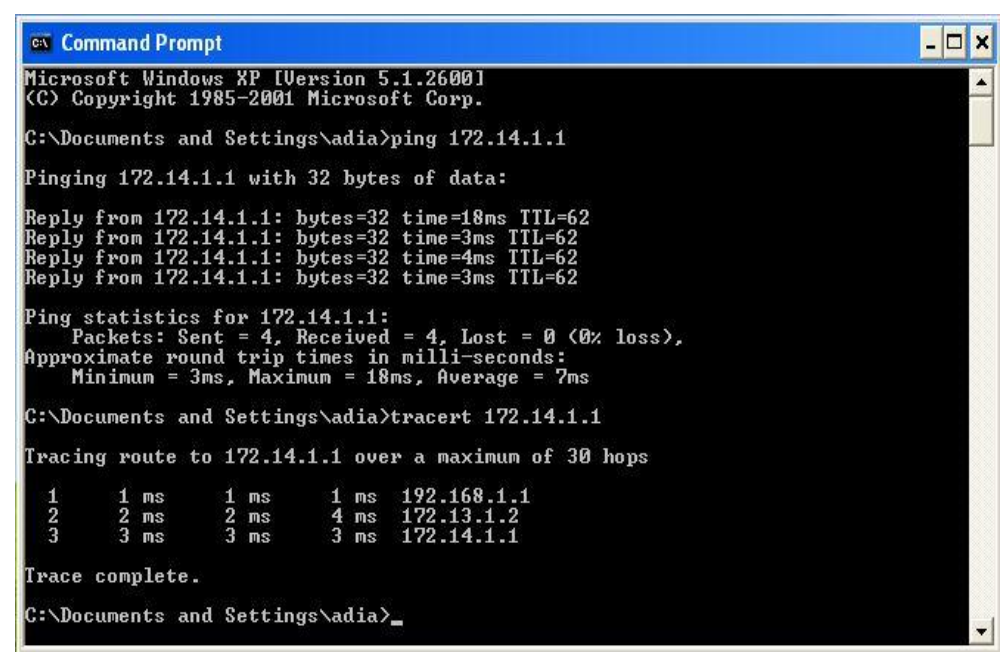

Gambar 20. Uji Jalur Pertama Menggunakan Ping dan Traceroute

\subsubsection{Jalur Kedua Best Path}

Jalur kedua best path, contoh diambil dari komputer client SMK UT PGII menuju router R1 yang telah ditandai dengan panah pada Gambar 21. Pada jalur best path yang kedua cost pada interface ether3 router R5 bernilai 20, cost kedua pada ether 2 router R3 bernilai 10, cost ketiga pada ether 2 router R2 bernilai 20, dan cost keempat pada ether 2 router $\mathrm{R} 1$ bernilai 30. Maka total keseluruhan cost pada jalur kedua sebesar 80 cost. 


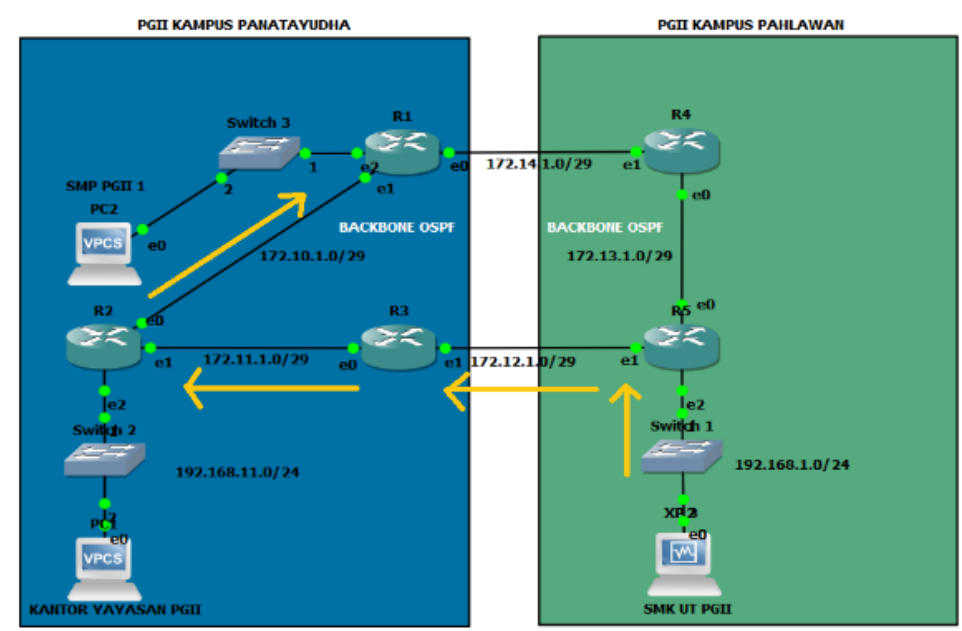

Gambar 21. Jalur Kedua Best Path

Pengujian jalur kedua menggunakan ping dan traceroute dapat dilihat pada gambar 22 di bawah ini.

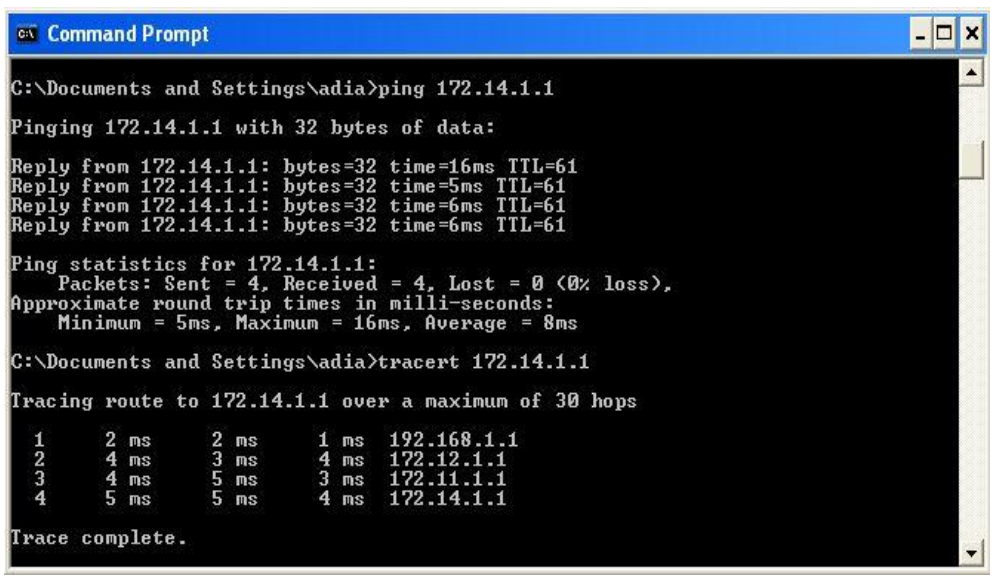

Gambar 22. Uji Jalur Kedua Menggunakan Ping dan Traceroute

\subsection{Prinsip Kerja Berdasarkan Dijkstra}

Pengujian ini, ukuran atau metric dijkstra yang ada pada setiap router yang telah terkonfigurasi oleh Routing OSPF dijumlahkan. Hasil dari penjumlahan tersebut akan menjadi parameter bagaimana metricmetric dijkstra mempengaruhi prinsip kerja SPF dalam mencari jalur terbaik.

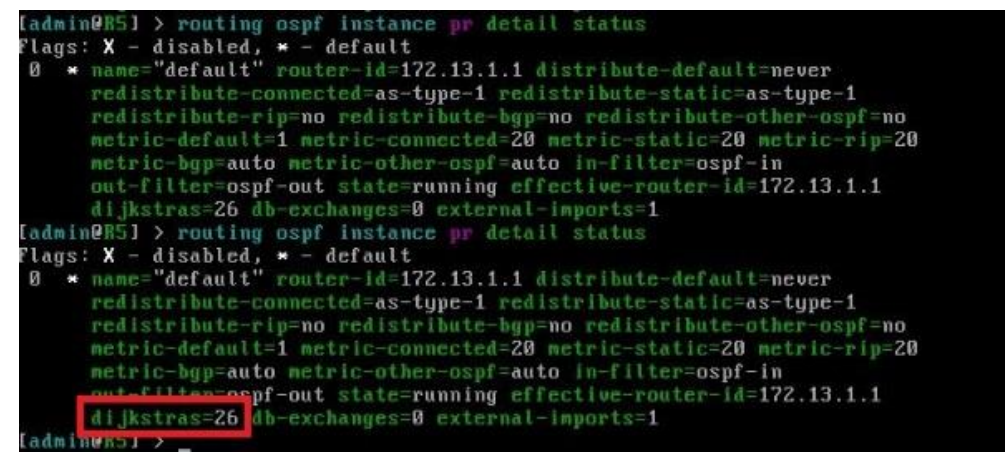

Gambar 23. Informasi Metric Dijkstra pada Router $\mathbf{R 5}$

Gambar 23 di atas menunjukkan bahwa ukuran atau metric dijkstra pada router R5 bernilai 26. Seperti yang dijelaskan sebelumnya bahwa SPF bersifat non-scalable yang artinya metric dijkstra yang bernilai 26 tidak dapat diubah. Nilai tersebut hanya akan berubah ketika router di shutdown atau di reboot dan ketika router telah beroperasi kembali metric dijkstra akan secara otomatis menentukan matric-nya sendiri. 
Selama pengujian berlangsung, nilai metric dijkstra pada router R1 bernilai 25, router R2 bernilai 22 , router $\mathrm{R} 3$ bernilai 25 , router $\mathrm{R} 4$ bernilai 30 .

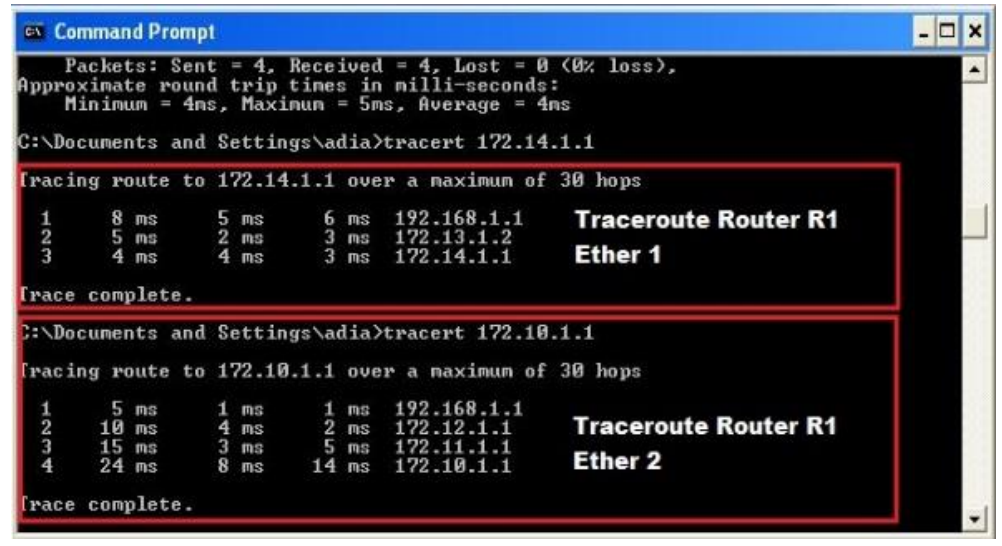

Gambar 24. Traceroute Menuju Ether1 dan Ether2 Router R1

Gambar 34 menampilkan proses traceroute menuju router R1 dari client SMK UT PGII kepada interface yang berbeda yaitu etherl dengan IP Address 172.14.1.1 dan ether2 dengan IP Address 172.10.1.1. Dari hasil traceroute tersebut diketahui bahwa untuk mengirimkan informasi menuju interface etherl di router R1 harus melewati jalur best path pertama dibandingkan melalui jalur best path kedua. Ini dikarenakan jumlah metric dijkstra dalam jalur best path kedua lebih besar daripada jumlah metric dalam jalur best path pertama. Untuk lebih jelasnya, dalam penelirian ini telah dillakukan perhitungan dari setiap metric dijkstra dari setiap router yang ada di jalur best path pertama dan kedua terdapat pada Gambar 25.

\begin{tabular}{|c|c|c|c|}
\hline Best Path 1 & Metric Dijkstra & Best Path 2 & $\begin{array}{c}\text { Metric } \\
\text { Dijkstra }\end{array}$ \\
\hline Router R5 & 26 & Router R5 & 26 \\
\hline Router R4 & 30 & Router R3 & 25 \\
\hline Router R1 & 25 & Router R2 & 22 \\
\hline & & Router R1 & 25 \\
\hline Jumlah & 81 & & 98 \\
\hline
\end{tabular}

Gambar 25. Jumlah Metric Dijkstra Pada Jalur Best Path Pertama dan Kedua

Kesimpulan yang dapat diambil dari pengujian serta perhitungan sistem kerja SPF pada Algoritma Dijkstra adalah SPF akan memilih jalur terbaik (best path) dengan nilai metric dijkstra yang lebih kecil daripada jalur terbaik (best path) lain yang memilik nilai metric yang lebih besar. Pada pengujian Redistribution dilakukan langkah serupa yaitu melakukan test dengan ping dan traceroute dari client SMK UT PGII menuju client SMP PGII 1. Hanya saja perhitungan dengan menjumlahkan nilai metric dijkstra dijumlahkan dengan nilai metric redistribute yang akan mempengaruhi pemilihan jalur terbaik dalam proses pendistribusian data. Seperti tercantum pada Gambar 25 bahwa nilai metric-static dan metricconnected di router R1 yang terhubung kepada client SMP PGII 1 masing-masing bernilai 20, maka nilai keseluruhan metric redistribute pada proses redistribution adalah 40. 


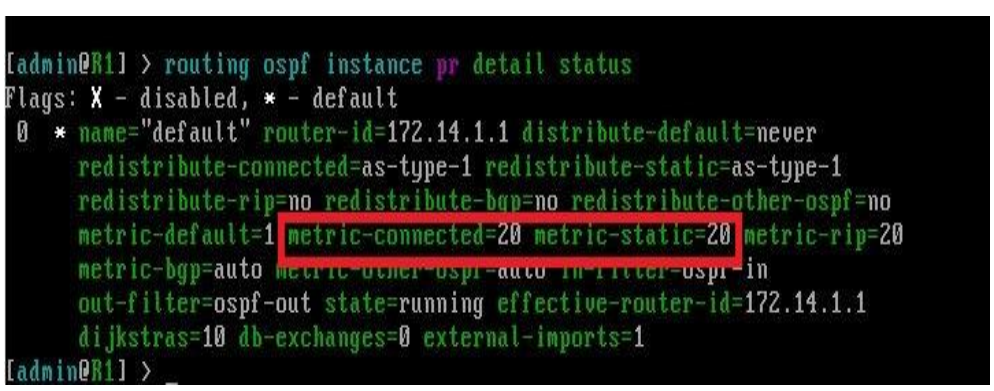

Gambar 26. Nilai Redistribute Pada Router R1

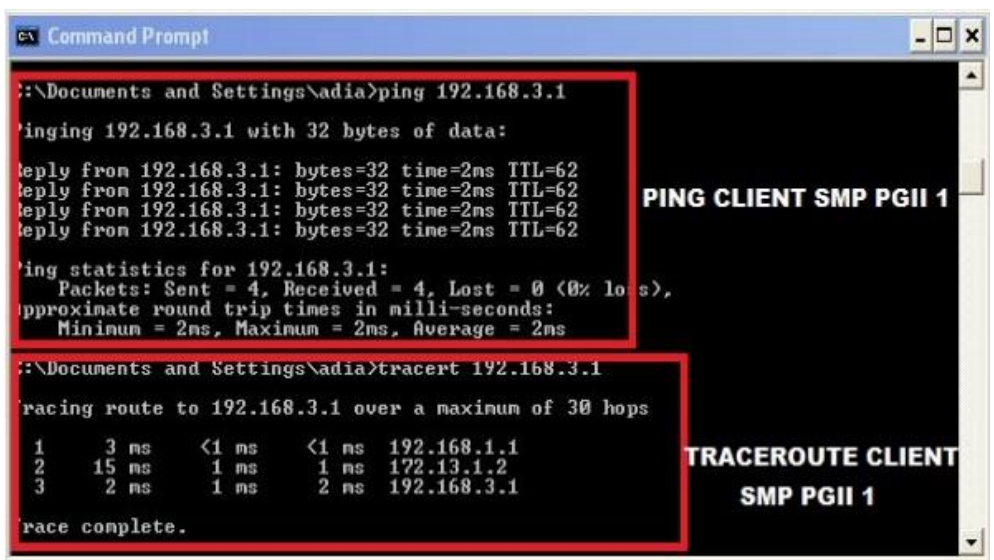

Gambar 27. Ping dan Traceroute Menuju Client SMP PGII 1

\begin{tabular}{|c|c|c|c|}
\hline Best Path 1 & Metric Dijkstra & Best Path 2 & $\begin{array}{c}\text { Metric } \\
\text { Dijkstra }\end{array}$ \\
\hline Router R5 & 26 & Router R5 & 26 \\
\hline Router R4 & 30 & Router R3 & 25 \\
\hline Router R1 & 25 & Router R2 & 22 \\
\hline $\begin{array}{c}\text { Jumlah } \\
\text { Dijkstra }\end{array}$ & $\mathbf{8 1}$ & Router R1 & 25 \\
\hline $\begin{array}{c}\text { Jumlah } \\
\text { Redistribute }\end{array}$ & $\mathbf{4 0}$ & $\mathbf{9 8}$ \\
\hline \begin{tabular}{c} 
Total \\
\hline
\end{tabular} & $\mathbf{1 2 1}$ & $\mathbf{4 0}$ & $\mathbf{1 3 8}$ \\
\hline
\end{tabular}

\section{Gambar 28. Metric Dijkstra Dijumlahkan Dengan Metric Redistribute}

Berdasarkan pada penjumlahan nilai metric dijkstra dengan metric redistribute dapat diambil kesimpulan bahwa jalur terbaik (best path) dengan nilai metric yang lebih kecil akan dipilih sebagai jalur pendistribusian terbaik dari best path lain yang memilik metric yang lebih besar. Selain itu, redistribution dapat menghubungkan routing dynamic OSPF dengan routing static yang terhubung pada masing-masing client.

\section{KESIMPULAN}

Kesimpulan yang didapat dari dari hasil implementasi dan penelitian yang telah dilakukan oleh adalah sebagai berikut:

a. Penggunaan Routing OSPF telah berhasil dilakukan pada jalur utama (backbone) untuk proses pendistribusian data dan komunikasi antar router dengan baik. 
b. Penggunaan Routing OSPF memudahkan pencarian jalur terbaik (best path) untuk pendistribusian data dan pengiriman informasi berdasarkan pada metric dijkstra didalam sistem kerja SPF.

c. Penggunaan Metode Redistribution dapat menghubungkan sebuah routing ke routing lainnya dan mampu memberikan pendistribusian yang baik bersama dengan Routing OSPF didalam pengembangan topologi jaringan yang ada di SMK UT PGII.

Beberapa saran yang dapat disampaikan adalah sebagai berikut:

a. Dalam pengembangan jaringan yang akan dilakukan SMK UT PGII bersama unit-unit sekolah lainnya yang berada dibawah Yayasan Pendidikan PGII Bandung, maka harus melakukan perubahan topologi jaringan yang ada.

b. Untuk memudahkan pendistribusian data dan pengiriman informasi dari satu router ke router yang lain dapat menggunakan Routing OSPF.

c. Untuk memberikan hasil terbaik dalam pendistribusian kepada masing-masing client dapat menggunakan Metode Redistribution.

d. Untuk penelitian selanjutnya dapat dikembangkan ke dalam proses routing, metode, dan topologi jaringan lainnya.

\section{DAFTAR PUSTAKA}

[1] Achmad. (2015). IMPLEMENTASI ROUTING PROTOCOL OPEN SHORTEST PATH FIRST(OSPF) PADA MODEL TOPOLOGY RING. ISSN 1979-276X Faktor Exacta 8(2): 92-99, 2015, 92-99.

[2] Dwiyanto, S., Putra, G. W., \& Krisnaningsih, E. (2015). Penerapan Ospf Routing, De-Militarized Zone, Dan Firewall Pada Mikrotik Routerboardtm Dinas Komunikasi Dan Informatika Depok. ISSN 2406-7768 Jurnal Sistem Informasi Volume.2, 2015.

[3] Edi, D. (2006). KAJIAN ALGORITMA ROUTING DALAM JARINGAN KOMPUTER. Jurnal Informatika UKM, Vol. II, No. 3, 47-55.

[4] Firmansyah, R. (2014). RANCANG BANGUN JARINGAN KOMPUTER DENGAN KABEL LISTRIK SEBAGAI MEDIA TRANSMISI UNTUK KOMUNIKASI DATA . Jurnal Informatika. Vol. II No. 2, 104-110.

[5] Firmansyah, R. (2018). KOMPUTER DAN JARINGAN DASAR. Bandung: PT. Humaniora Utama Press.

[6] Le, F., Xie, G. G., \& Zhang, H. (2008). Understanding Route Redistribution. International Conference in Network Protocols (ICNP) (pp. 2-12). Beijing: International Conference in Network Protocols (ICNP).

[7] Masykur, F. (2016). PENGGABUNGAN ANTAR ROUTING PROTOCOL MENGGUNAKAN TEKNIK REDISTRIBUTION. ISBN: 978-602-1180-33-4 Prosiding SNATI F Ke - 3 Tahun 2016, 3942.

[8] Munandar, A., \& Badrul, M. (2015). PENERAPAN OPEN VPN IPCOP SEBAGAI SOLUSI PERMASALAHAN JARINGAN PADA PT.KIMIA FARMA TRADING \& DISTRIBUTION . ISSN. 2442-2436 JURNAL TEKNIK KOMPUTER AMIK BSI VOL. 1 NO. 1 FEBRUARI 2015.

[9] Nurhayati , A., \& Pangestu, A. (2016). SIMULASI ROUTING PROTOKOL BERBASIS DISTANCE VECTOR MENGGUNAKAN GNS3 VERSI 0.8. . ISSN 1412-0372 JETri, Volume 13, Nomor 2, Februari 2016, Halaman 87 - 101, 87 - 101.

[10] Saindra, G., \& Pulungan, R. (2012). Reduksi Parameter Quality-Of-Service Menggunakan RoughSet-Theory Dalam Simulasi Routing Algoritma Dijkstra. ISSN: 1978-1520, IJCCS, Vol.6, No.1, January 2012, pp. 79 90, 79 - 90.

[11] Saputra, D. (2016). IMPLEMENTASI VIRTUAL PRIVATE NETWORK PADA SISTEM INFORMASI PENGELOLAAN KEUANGAN DAERAH PEMERINTAH PROVINSI RIAU. ISSN : 2301-4474, Vol. 6, No. 2, Desember 2016, 18-31.

[12] Sofana, I. (2011). Teori dan Modul Praktikum Jaringan Komputer . Bandung: Modula.

[13] Towidjojo, R. (2016). MIKROTIK KUNG FU, KITAB 4. Palu: Jasakom.

[14] Utomo, P., \& Purnama, B. E. (2012). Pengembangan Jaringan Komputer Universitas Surakarta Berdasarkan Perbandingan Protokol Routing Information Protokol (RIP) Dan Protokol Open Shortest Path First (OSPF) . ISSN: 2302-5700 IJNS - Volume 1 Nomor 1 - November 2012, 8-25.

[15] Yani, H., Yusia, P. A., \& Rohayani, H. (2013). Analisis dan Perancangan Sistem Manajemen Network Berbasis Virtual Local Area Network (Studi Kasus : PT. Sumbertama Nusa Pertiwi). ISSN: 23023805 Seminar Nasional Teknologi Informasi dan Multimedia 2013, STMIK AMIKOM Yogyakarta, Januari 2013, Halaman 21-25, 21-25 